\title{
Reflexiones sobre el canon de la poesía españo- la femenina a partir del 2000. Tres paradas en el camino: Raquel Lanseros, Ana Merino y Yolanda Castaño
}

\author{
Remedios SánCHEZ GarCía \\ Universidad de Granada
}

\begin{abstract}
En el presente artículo se realiza un estudio sobre las poéticas femeninas del siglo XXI, centrado en las tres autoras más significativas nacidas en los años setenta en España según El canon abierto. Última poesía en español; en concreto Raquel Lanseros, Ana Merino y Yolanda Castaño. Cada una de ellas, desde su personal identidad literaria, responde a unas prioridades éticas y estéticas, utilizando una perspectiva más narrativa que en generaciones anteriores, en las que la infancia, el inexorable paso del tiempo, la historia de España y el erotismo son temas que subyacen y construyen unas obras poliédricas y heterogéneas.
\end{abstract}

Keywords: poesía española femenina, canon contemporáneo, Raquel Lanseros, Ana Merino, Yolanda Castaño

\section{Introducción. Para un nuevo concepto de canon}

En el ámbito de la Literatura, si hay algo que ha propiciado intensas polémicas, ha sido buscar una definición de canon que acabe por convencer a una mayoría de los estudiosos. Obviamente, resulta bastante complejo, precisamente porque estamos hablando de un arte y no de una ciencia exacta, desvincular el concepto de canon literario del de gusto estético dominante en un momento histórico determinado. Pero, seguramente, un punto de partida en el que todos podríamos estar de acuerdo es en que tiene que haber algún mecanismo de selección de textos dentro del corpus estético tan amplio y heterogéneo de cada época.

Esas obras, si sobreviven una vez que han pasado por el tamiz balsámico que es el tiempo y siguen suscitando el entusiasmo del público lector, deben conformar una suerte de selección representativa de la estética de un momento literario. Porque, como asevera Pozuelo Yvancos, «los valores estéticos son cambiantes, movedizos y fluctúan en función del periodo histórico en el que nos encontremos» ${ }^{\mathrm{I}}$. Esto si lo miramos con perspectiva histórica pero también con algo de ingenuidad -buscada, claro-porque la Historia de la Literatura, con mayúsculas, o de cualquier cosa, la escriben los vencedores. Y también hay vencedores y vencidos en poesía, que nadie se llame

I José María Pozuelo Yvancos, «Canon: estética o pedagogia», Ínsula, 60o, 1996, pp. 3-4. 
a engaño².

Fundándonos en esta idea de que existe un canon que eligen para perdurar los teóricos estudiosos de los vencedores, si lo planteamos desde un enfoque puramente epistemológico, ¿quiénes son las personas, esos sabios, que determinan lo que debe conformar o no el canon? ¿Quién marca lo que no debe perderse, lo que hay que preservar contra viento y marea? Y, ¿atendiendo a qué criterios se ha venido haciendo? Escribe Mainer que, «en la literatura, casi todo es contienda, porque siempre está de fondo la constitución de un mercado literario y la pugna de las hegemonías»³. Efectivamente.

Hasta ahora, había un grupo muy selecto de cultos bibliófilos de cada época, dueños del «capital cultural» que, al ser «poseedores de la nobleza cultural» de la que hablaba Bourdieu ${ }^{4} \mathrm{y}$, por tanto, capaces de conocer la inmensidad de la literatura de una lengua, o de un país (que, en el ámbito del español aunque a veces se nos olvida, no son la misma cosa), construían, cada uno desde su singularidad y su percepción, un proyecto de canon. Pero en las circunstancias actuales ha habido un boom de publicación: la literatura es una realidad polisistémica (lo aclara Even-Zohar ${ }^{5}$ ) y -y cada vez más- un mercado multimedia, un producto de consumo fruto de una realidad ideológica plural que, una vez terminado por el autor, el mercado (con todos los condicionantes que ello implica) lo acerca a un lector capaz de interpretar el texto a partir de su percepción del mundo, normalmente con un código social común entre ambos, si hablamos de la literatura contemporánea. El hecho literario crea un mundo compartido, dice Luis García Montero ${ }^{6}$.

Eso hace muy complejo el trabajo del nuevo investigador de la literatura que, para hablar con propiedad, debiera cumplir con la mínima obligación de conocer los textos. Y una única persona no tiene, en mi opinión, capacidad para abarcar el inmenso caudal de palabras (buenas y malas) que dicen en este tiempo que son poesía.

\section{El canon está abierto. Poetas nacidas a partir de 1970}

Por lo tanto, el punto de partida, no debiera estar en poner el foco sobre

\footnotetext{
2 Estas reflexiones están ampliadas en la obra de María Remedios Sánchez García, El canon abierto. Última poesía en español, Madrid, Visor, 2015.

3 José Carlos Mainer, El último tercio del siglo. Antología consultada de la poesía española, 1968 -I998, Madrid, Visor, I998, p. II.

4 Pierre Bourdieu, La distinción. Criterios y bases sociales del gusto, Madrid, Taurus, I998, p. 23.

5 Itamar Even-Zohar, «Factores y dependencias de la cultura. Una revisión de la teoría de los Polisistemas», en Montserrat Iglesias Santos (ed.), Teoría de los Polisistemas, Madrid, Arco Libros, 1999, pp. 22-52.

6 Luis García Montero, Un velero bergantín, Madrid, Visor, 2014.
} 
el valor del libro, sino, en primera instancia, en quién/quiénes emiten esa opinión de legitimación/deslegitimación. Como ya avisara Mignolo, «Preguntas como quién decide por quién y por qué debería leerse un grupo de textos determinado tomarán el lugar de preguntas como qué se debería leer» ${ }^{7}$. Está claro, como afirma Sullá, que el canon se debe analizar como «una lista o elenco de obras consideradas valiosas y dignas por ello de ser estudiadas y comentadas ${ }^{8}$. Y para construir ese elenco, ya no puede hacerse desde la minoría de sabios lectores, sino desde una mayoría de estudiosos que, en la época contemporánea multicultural, dedican sus esfuerzos y su tiempo a desgranar la poesía última, trabajando en equipo, o, por lo menos, no siempre a la contra como en otro tiempo. Porque, como ya aclaraba Talens ${ }^{9}$, la concepción de la literatura actual viene marcada por una serie de claves: escritura, lectura, interpretación, difusión y enseñanza. Sin eso, el camino es difícilmente transitable.

Requiere esta idea una profundización mayor teórica y práctica con una prioridad que nos devuelve al principio: el concepto de calidad y riqueza cultural $^{10}$ integrado en la lucha dialéctica, dentro del sistema, entre lo que ya está canonizado y lo que pretende integrarse dentro de ese canon que evoluciona conforme evoluciona la cultura y la sociedad en que se produce. Eso obliga al escritor a estar también siempre en constante perfeccionamiento, pues el lector abandona un libro en cuanto le resulta incomprensible o ajeno a sus intereses.

Entre otras razones porque, siguiendo el planteamiento de Bourdieu, «la lógica de la moda $»^{\prime \prime}$, que es capaz de condenar una tendencia, una corriente o una escuela $-\mathrm{o}$, añadimos nosotros, intentar ignorarla como sucede a menudo en España- con la excusa de que «está superada», solo deja en ridículo a determinados críticos porque el mercado, las editoriales, tienen mecanismos para hacer llegar las obras al público lector. Y resulta peligroso eso de que el investigador de la literatura funcione al margen de la sociedad condicionado solo por intereses extra-literarios o poco relacionados con nuestro ámbito de estudio. Peligroso especialmente para él, claro, porque los lectores han descubierto el secreto: no somos infalibles y, a fuer de intentar legitimar algo por la fuerza o por el llamado «efecto de la titulación» del que

7 Walter Mignolo, «Los cánones y (más allá de) las fronteras culturales (o ¿de quién es el canon del que hablamos?)», en El canon literario, ed. Enric Sullá, Madrid, Arco-Libros, 1998, p. 256.

8 Enric Sullà, «El debate sobre el canon literario», en El canon literario, op. cit., p. I2.

9 Jenaro Talens, «El lugar de la Teoría de la literatura en la era del lenguaje electrónico», en Curso de Teoría de la Literatura, coord. Darío Villanueva, Madrid, Taurus, 1994, p. 139.

IO Iuri Lotman, «Text within a text», Soviet Psychology, 26, 1988, pp. 74 y ss.

II Pierre Bourdieu, State Nobility: Elite Schools in the Field of Power, Cambridge, Polity Press, 1998, p. 192. 
hablaba Bourdieu ${ }^{12}$, queda deslegitimado al final.

El canon actual ya no puede verse desde aquella superioridad moral de una clase dirigente tradicional, como si hubiese que decidir desde arriba lo que deben leer los de abajo. Son ahora «los de abajo», los lectores, los que dan las claves para construir un canon que se base en qué libros son los que se leen y qué autores interesan. Otra cosa es, cuando menos, ridícula y, cuando más, una muestra de absurda soberbia. Y no se puede plantear desde la ruptura con todo lo anterior. Ha recordado García Montero la importancia del

reconocimiento de una herencia que perfila al mismo tiempo la conciencia individual de nuestros deseos y el reconocimiento de nuestra deuda con los demás. El derecho a admirar merece ser cultivado en estos tiempos. Forma parte de la ética de la resistencia dentro de una sociedad dominada por el descrédito ${ }^{13}$.

Descrédito, también ante lo literario y ante la visión tradicional del canon.

El canon debiera entenderse como algo permanentemente abierto a lo nuevo, y más allá del mercantilismo y del marketing, como una elección (eso no va a cambiar, siempre hay que elegir) de los referentes valiosos que funcionan como espejo cultural e ideológico de la identidad social en la línea de lo expuesto por Sullá ${ }^{14}$ que marcan las claves literarias concretas de cada momento. Pero no elaborado por un individuo al que otros siguen, sino como fruto de muchas voces, un canon construido aprovechando la coralidad de los estudiosos que, desde su independencia y sus años de estudio, analizan aquello que saben. La suma de una diversidad de voces autorizadas por el trabajo y el estudio, sin rencores ni resentimientos, seguramente, nos acercan más a esa norma y hace habitable el ambiente literario. De esa suma de elecciones, quedará, con el paso del tiempo, una mínima parte, la quintaesencia que formará parte de algo mucho más amplio, la perspectiva diacrónica del canon que no se puede decidir en este momento sobre los autores que están en pleno proceso de creación de su obra, depurando su voz en una suerte de constante reinventarse a sí mismos, mirando hacia adentro y hacia afuera (es decir, ética y estética) en la permanente búsqueda/negociación de su identidad y del significado del mundo en el que se inserta por acción u omisión, del verso luminoso que hará que un poema sea perfecto, útil al otro. Pero para llegar a los estudios diacrónicos hay que empezar por los sincrónicos y por ir sumando prácticas poéticas, nuevas conquistas de la palabra en el poema y teorizaciones claras desde el rigor y la responsabi-

I2 Pierre Bourdieu, State Nobility: Elite Schools in the Field of Power, op. cit., p. 23

I3 Luis García Montero, Un velero bergantín, op. cit., p. 37.

I4 Enric Sullà, El canon literario, op. cit., p. II. 
lidad. Para lograr la voz en plural que tanta falta hace en la literatura contemporánea.

\section{Las poetas nacidas en los años 70}

En 2015, un grupo de investigadores y críticos literarios decidimos tratar de elaborar una cartografía real de lo que estaba sucediendo en la poesía en español. Numerosos monográficos de revistas con cierto tono parcial (algunos radicalmente sesgados), antologías (que más que eso eran antojo-logías) y obras de similar perfil obligaban a poner un poco de orden en la biblioteca desde el necesario consenso. Por eso elaboramos una encuesta, verificada notarialmente desde sus bases hasta los resultados, en la que se solicitaban cinco nombres de poetas nacidos entre 1970 y I985, a ser posible de, al menos, dos nacionalidades. Recibimos 197 respuestas de estudiosos pertenecientes a I09 universidades de todo el mundo y a diversos medios de reconocido prestigio internacional. Pero de ello da cuenta pormenorizada El canon abierto. Última poesía en español (2015) ${ }^{15}$ y ahí podrá consultarse todo el proceso. Los cuarenta primeros poetas, siguiendo el orden del número de apoyos, fueron Fernando Valverde (España), Raquel Lanseros (España), Jorge Galán (El Salvador), Elena Medel (España), Alí Calderón (México), Andrés Neuman (Argentina), Federico Díaz Granados (Colombia), Andrea Cote (Colombia), Ana Merino (España), Lucía Estrada (Colombia), Xavier Oquendo (Ecuador), Álvaro Solís (México), Carlos Aldazábal (Argentina), Sergio Arlandis (España), Antonio Lucas (España), José Luis Rey (España), David Cruz (Costa Rica), Victoria Guerrero (Perú), Yolanda Castaño (España), Pablo García Casado (España), Josep María Rodríguez (España), Daniel Rodríguez Moya (España), Frank Báez (República Dominicana), Javier Bello (Chile), Luis Enrique Belmonte (Venezuela), Hernán Bravo Varela (México), Gabriel Chaves (Bolivia), Catalina González Restrepo (Colombia), Roxana Méndez (El Salvador), Julián Hérbert (México), Héctor Hernández Montecinos (Chile), Aleyda Quevedo (Ecuador), Erika Martínez (España), Francisco Ruiz Udiel (Nicaragua), Javier Alvarado (Panamá), Luis Felipe Fabre (México), Mijail Lamas, (México), Mario Meléndez (Chile), Urayoán Noel (Puerto Rico) y Luis Bagué (España).

De aquí me interesa destacar que solo hay, entre esos cuarenta principales, si se me permite la expresión, once mujeres y, de ellas, cuatro españolas que cito por orden de sufragios: Raquel Lanseros (1973), Elena Medel (I985), Ana Merino (I97I) y Yolanda Castaño (I977). Resulta muy curiosa la selección, habida cuenta los perfiles tan diversos de las tres seleccionadas

I5 Remedios Sánchez García, El canon abierto. Última poesía en español (Selección de poemas de Anthony Geist), Madrid, Visor, 2015. 
(es decir, las nacidas en los años setenta), de las que procede ahora trazar las claves de su personalísima voz poética.

\section{I. Raquel Lanseros, palabra heredada en el tiempo}

Si hay una voz premiada y que exponencialmente va desarrollándose en los últimos quince años, esa es la de Raquel Lanseros. Representa a una generación de autores que se identifican con la tradición, en plural, a una generación que ha leído con hondura la literatura angloamericana y las tradiciones francesa y alemana para conjugar esas lecturas a la par de la española. Recientemente acaba de reunir sus obras publicadas hasta el momento bajo el título de Esta momentánea eternidad (2016), lo cual facilita al lector una perspectiva de conjunto revisitando toda su trayectoria desde aquel iniciático Leyendas del promontorio (2005) en el que el que se desvelaban ya las maneras de alguien que ha reflexionado mucho sobre unas lecturas heterogéneas (de Rilke a Fray Luis de León, de Sabines a César Vallejo, de Keats a Unamuno o Schopenhauer), hasta el último aparecido hace tres años, Las pequeñas espinas son pequeñas (2013), donde se percibe ya una voz bien definida.

La escritora leonesa (aunque nacida en Jerez de la Frontera) demuestra el dominio de la palabra, la cercanía al otro, con un reborde culturalista que en este caso no es distanciador, sino que pretende implicar a quien tiene el libro entre las manos en esa búsqueda de nuevos horizontes y modos de interpretar la vida. Siguiendo a Antonio Machado, que parece ser uno de sus escritores de cabecera, Lanseros afronta la vida como la senda que existe entre lo finito y lo infinito (en palabras del Nobel Joseph Brodsky que ella misma cita en el prólogo), entre lo sabido a fuerza de golpes vallejianios y las certezas por donde transitamos, muchas veces a ciegas y otras, con ese destello de lucidez momentáneo que da la intuición. Y mucho de intuición, superadas rápidamente las Leyendas del promontorio (2005), había en las tres partes que componen Diario de un destello (2006), que, con su sensibilidad intimista reivindicativa, fue accésit del Premio Adonáis y que tiene en la hondura lírica de poemas como «Doña Juana» la justificación del interés que, desde entonces, ha venido suscitando la poeta.

Luego siguió ahondando en su voz interior con un tono intensamente meditativo en Los ojos de la niebla (2008) que tiene su punto álgido en «Beatriz Orieta. Maestra Nacional (I9I9-I945)» con versos como «El silencio es de mármol / El silencio / es la respuesta de todas las preguntas» ${ }^{16}$; más tarde, con Croniria (2009), fusión de kronos y oniria creada ad hoc, centra su interés en el paso del tiempo y la forma en que se transforman las ilusiones («quien

I6 Raquel Lanseros, A las órdenes del viento, Granada, Valparaíso, 2012, p. 56. 
lo ha perdido todo varias veces / reconoce el honor de una derrota», acaba «Canción de la trinchera» ${ }^{17}$. Y, finalmente Las espinas pequeñas son pequeñas (2013) representan la madurez de una mujer que se (re)construye cada día volviendo a sus orígenes con el recuerdo de sus ancestros en «Compatriota de los robles», esos que le han ido ayudando a forjar una identidad personal que trasciende aquello de Pessoa de que el poeta es un fingidor. No son Las espinas... una obra de fingimiento emocional, sino de decidido compromiso con una generación poco reconocida, la que sufrió la Guerra Civil y la dictadura; el poemario hunde sus raíces en la deuda con el pasado para construir un futuro en el que no cabe el olvido. Efectivamente, en esa línea está el verso con que acaba el «Himno a la claridad», «No hay verdad más profunda que la vida $»^{18}$ y Raquel Lanseros parece haberla vivido con entusiasmo y sabido mirar cara a cara la realidad con los ojos ingenuos de una niña, pero con la madurez suficiente para saber interpretarla, parafraseando a Daudet.

Los doce inéditos que cierran Esta momentánea eternidad nos muestran el presente poético de la autora, marcado con una palabra que parece resultar faro y guía de su pensamiento: compromiso con esa tradición, con la herencia recibida. Con textos como «Sigue doliendo España», donde escribe con serena lucidez «España mía, al borde de tus páramos / las amapolas gritan el nombre de mil muertos $»^{19}$, se nos revela que, seguramente, era el momento propicio para hacer esta obra recopilatoria. Si la poesía es una aproximación a lo absoluto por medio del símbolo, como afirmaba Juan Ramón Jiménez, Raquel Lanseros avanza, con su voz singular, honda y firme, en ese camino eterno de trascender el símbolo y humanizarlo, de hacerlo cercano uniendo pensamiento con sentimiento para devolverlo a los lectores, que son los dueños verdaderos del fuego sagrado que contienen las palabras.

\subsection{Ana Merino, la infancia es una patria}

Ana Merino tiene una trayectoria poética que supera los veinte años desde aquella primera obra, Preparativos para un viaje (1995), con la que obtuvo el premio Adonáis. Reside en Estados Unidos desde esa época, lo cual, teóricamente, podría haberla distanciado del interés del público español, pero no ha ido así. Desde entonces se han sucedido obras como Los días gemelos (1997), La voz de los relojes (2000), Juegos de niños (2003), Compañera de celda (2006), Curación (2010) y Los buenos propósitos (2015). Las tres primeras obras conforman una trilogía donde se produce una intensa reflexión, cada vez más honda, sobre lo que implica el viaje; pero no ya solo el viaje como algo físico, sino como algo que va a condicionar lo emocional. El viaje como cam-

I7 Raquel Lanseros, op. cit., p. 78.

I8 Raquel Lanseros, op. cit., p. 93

I9 Raquel Lanseros, Esta momentánea eternidad, Madrid, Visor, p. I42. 
bio en el que se percibe una mirada nómada que se resiste a desarraigarse de sus orígenes de su cultura, de su tradición («¿De dónde soy? / Soy de lo que leo $»^{2 \circ}$ ), escribe en La voz de los relojes (2000).

El cierre de la trilogía con este poemario supone una evolución, una vuelta de tuerca hacia un camino distinto, más directo, más rotundo y narrativo, con versos mucho más transparentes para retratar, a veces como quien pone el foco de una cámara, lo que sucede a su alrededor en un mundo cada vez más deshumanizado desde el que mira los horizontes usando como herramienta un intimismo, casi ensoñativo, pero jamás evasivo. Se ve claramente en Compañera de celda (2006), donde hay un obvio compromiso con los desheredados del mundo. Merino afronta la realidad, el paso del tiempo, los cambios, la desigualdad social y la injusticia tomando la palabra como herramienta de liberación para poner negro sobre blanco la verdad de su mirada. Y la tradición la entiende como «la memoria compartida, un punto de referencia al que siempre se puede retomar», en opinión de Sánchez-Mesa ${ }^{21}$.

A pesar de todo, la poeta no pierde de vista la infancia que es un refugio, el recuerdo del hogar perdido y reconstruido, ya en soledad y en otro lugar pero desde un estoicismo resignado. Luego, en Juego de niños (2003) Morales Barba percibe «una pulsión por ser feliz y avanzar contra o con los monstruos que siempre te acompañan y donde la vida 'es un enigma del que descifro / solo un trozo de esperanza' $»^{22}$. Pero siempre desde un corte que entronca con lo metafísico y la preocupación por la ausencia y el tiempo perdido/pasado con reborde melancólico y existencialista. Porque, de fondo, siempre resuena esa preocupación por el tiempo, interior y exterior, como circunstancia vital que marca los límites de lo que podemos y no podemos hacer. La poeta madrileña quisiera, a veces, parar ese tiempo, recrearse en el instante, diseccionarlo con la mirada a modo de bisturí, pero todo pasa con la rapidez de ráfaga y aprehender esos momentos («con un reloj de arena / señalo los horarios / de la desesperanza $»^{23}$, dice en unos versos que reflejan cómo ese paso del tiempo, desde el punto de vista temático, se ha convertido en una obsesión honda que le marca el camino como una brújula serena pero firme. Profundiza en Curación (20I0) desde un mayor soporte irracionalista en ese yo y en la fragilidad del cuerpo y de la existencia; pero serán las dos partes que componen Los buenos propósitos (2015) los que nos den la voz de una autora en plenitud, que va en este momento, de la abstracción a la

20 Ana Merino, La voz de los relojes, Madrid, Visor, 200o, p. 9.

2I Domingo Sánchez Mesa (ed.), Cambio de siglo. Antología de poesía española 1990-2007, Madrid, Hiperión, 2007, p. 469.

22 Rafael Morales Barba, La musa funámbula: la poesía española entre 1980 y 2005, Madrid, Huerga y Fierro, 2008, p. 289.

23 Ana Merino, La voz de los relojes, op. cit., p. 47. 
cotidianeidad, ya asentada en su quehacer, sabiendo que su camino, cargado de ironía y de ternura semi-oculta, para desentrañar las contradicciones existenciales diarias en las que cualquier persona anda inmersa. Y, así, el poema se convierte en vida presente y en voz de muchedumbre.

\subsection{Yolanda Castaño, buscando el idioma de Eros}

El cuerpo tiene un valor esencialista en toda la obra de la gallega Yolanda Castaño. El eros y su narración explicitada, fusionando el verso con otras disciplinas creativas como las artes plásticas o la música. Es conveniente reiterar su condición de gallega porque ella escribe en gallego y posteriormente lo traduce al español, que no es un dato nada baladí pero en el que, por cuestión de espacio, no podemos profundizar aquí. Se inicia su trayectoria con Elevar as pálpebras (1995), pero será primera obra bilingüe, Vivimos en el ciclo de las Erofanías (200o), que había sido Premio de la Crítica Gallega en I998, la que realmente la sitúe como una voz interesante en el panorama de la joven poesía española.

Después vinieron, también siempre en ediciones bilingües, El libro del egoísta (2006), Profundidad de campo (2009) y La segunda lengua (2014), una reflexión mucho más serena y metafórica que la de poemarios anteriores sobre la correlación vida-escritura, y esa escritura poética como testimonio de vida, siempre indagando sobre ése lenguaje del cuerpo, la necesidad de comunicación cuya prioridad es su búsqueda constante usando las herramientas más actuales (valgan como ejemplo sus videopoemas) y la interacción entre diferentes artes. En palabras de Tua Blesa referidas a esta obra:

El mencionado uso de los metalenguajes hace del lenguaje ya uno de los temas, siendo otro fundamental, el cuerpo así como el deseo o el amor, como en anteriores libros de la autora. También continúa aquí un lenguaje que esquiva el realista o directo, y las imágenes y tropos dan profundidad al discurso de un libro brillante ${ }^{24}$.

Y todo dentro de un discurso que se va construyendo progresivamente con la pulcritud y la serenidad que procura el tiempo bien aprovechado.

24 Túa Blesa, «La segunda lengua», El Cultural, 24/4/2015, consultable bajo el enlace http:// www.elcultural.com/revista/letras/La-segunda-lengua/36335 [28.2.2017]. 


\section{Conclusiones}

Reflexionaba García-Posada a mediados de los años noventa a propósito del factor que definía el nuevo clima poético para la llamada «Generación 2000» a la que, teóricamente, vinieron a definir así los teóricos del momento (García Posada y García Martín, fundamentalmente; Luis Antonio de Villena, con matices, fundados en su hondo conocimiento de la poesía joven española); la percepción de García-Posada era que «se trata de algo que podríamos llamar vitalismo. Es decir, se renuncia, en un proceso lento, al autotelismo estético, que es sustituido por un vitalismo de fondo $»^{25}$. En esa misma línea, Luis Antonio de Villena considera que hay dos planteamientos:

intensificación del realismo (nueva poesía social, realismo sucio) que debía implicar también mayor presencia de la cotidianidad, incluso antipoética, o indagación en la hondura psíquica, en los campos menos expresados de la propia interioridad ${ }^{26}$.

Y, efectivamente, con las tres autoras españolas principales de esta generación (Raquel Lanseros, Ana Merino y Yolanda Castaño) estamos ante una poesía profundamente vitalista, habitualmente más narrativa que en anteriores generaciones aunque sin perder la necesaria musicalidad, que implica una indagación en el yo desde esa perspectiva de retrotraerse a la infancia (Merino), a la Historia -con mayúsculas- de los abuelos y la Guerra Civil española con sus sufrimientos (Lanseros), con presencia clara del erotismo (Castaño) y ciertos rebordes culturalistas que no implican una distancia del lector medio de poesía. Estamos ante unas poetas que saben su camino, que han encontrado una voz propia y personal y que tienen una larga trayectoria para seguir demostrando un talento que ya, a estas alturas, es algo más que una certeza.

25 Miguel García-Posada, «Del culturalismo a la vida», en Luis Muñoz (ed.), El lugar de la poesía, Granada, Diputación Provincial, 1994, pp. I7-I8.

26 Luis Antonio de Villena, Teorías y poetas, Valencia, Pre-Textos, 2000, p. 105. 